\title{
AC 2008-388: ENGINEERING WORLD HEALTH: LESSONS LEARNED FROM SIX YEARS OF UNDERGRADUATE SERVICE-LEARNING IN THE DEVELOPING WORLD
}

Robert Malkin, Duke University

Dr. Robert Malkin is the director of Engineering World Health and a Professor of the Practice of Biomedical Engineering at Duke University in Durham, North Carolina. 


\title{
Engineering World Health: \\ Lessons Learned from Six Years of Undergraduate Service- Learning in the Developing World
}

\begin{abstract}
Engineering World Health is a fusion of engineers, scientists and physicians donating their time and talents to improve healthcare in disadvantaged areas around the world. The Duke University-Engineering World Health (Duke-EWH) Summer Institute is a unique study abroad program that offers engineering students an opportunity to receive hands-on technical skills in a foreign country.

The summer begins with an intensive, four-week training session and ends with a four-week internship in a developing world hospital. Students install and repair equipment, train the staff, take inventory, solve problems and perform many other engineering duties at the hospital.

Objective measures of success include the fact that the students have placed back into service over 1000 pieces of medical equipment in 23 of the world's poorest hospitals. Students in the program have gained over 30,000 hours of hands-on experience working with medical equipment in the clinical setting.

With over 100 alumni of the program, Duke-EWH has amassed a significant amount of understanding of what works and what does not. For example, we now have a post-experience conference. We place students in pairs in developing world hospitals. Our training month now includes information on how to train across cultural and linguistic barriers.
\end{abstract}

\section{Introduction}

Engineering World Health is a fusion of engineers, scientists and physicians donating their time and talents to improve healthcare in disadvantaged areas around the world. The Duke University-Engineering World Health (Duke-EWH) Summer Institute is a unique study abroad program that offers engineering students an opportunity to receive hands-on technical skills in a foreign country. The program is open to undergraduate and graduate students in engineering, chemistry or physics degree programs.

With over 100 alumni of the program, Duke-EWH has amassed a significant amount of understanding what works and what does not. This paper reviews some of the most effective and least effective of these policies.

First, however, a bit of background on the structure of EWH might be helpful. EWH is a nonprofit organization based in Memphis, TN. EWH subcontracts all aspects of running the DukeEWH Summer Institute to Duke University, with the exception of maintaining relationships with the hospitals, a responsibility that rests with EWH. The Duke-EWH summer institute is run by the Director and Assistant Director with 2-3 part-time staff being brought in as needed during the spring and fall. During the summer, an additional 4 US staff and 2 local staff are engaged to live and work with the students in their host countries. 


\section{The Summer Program}

Adequate delivery of medical care often depends on sophisticated technology; technology that many underdeveloped countries cannot maintain in good working order. About $60 \%$ of donated equipment in the developing world is not being used. In many hospitals, their problem is not getting more donated equipment; it is keeping the equipment they have working. The developing world has a tremendous need for engineering support to repair and maintain their medical equipment and a need for training and resources so they can someday maintain their own equipment staff. While there are many organizations that donate equipment or medical care, only Duke-EWH sends undergraduate engineering majors into the developing world to repair and maintain medical equipment.

Undergraduates are recruited at national conferences and through e-mails and printed newsletters. In 2007, about 60 applications were received for 40 positions. In 2008, the ratio was two applications for each position. Applications were reviewed by a committee of faculty from four universities across the US. In 2008, Duke-EWH is expecting to host 50 participants.

We expect almost all participants to be engineers. In 2007, participants come from all over the US, and indeed the world. Applicants came from places like MIT, WPI, Duke, Johns Hopkins, Marquette, and also The University of Bath, The University of Waterloo and many other universities.

\section{The First Four Weeks}

Every participant receives at least four weeks of training on medical equipment in the developing world, how to train across cultural barriers, and four weeks of technical Spanish (if their host hospital is in Central America) or Swahili (if their host hospital is in Tanzania) language training. In all cases, students are staying with local families during the first four weeks. The language training is a course that EWH developed with ALE (Academia Latinoamericano de Espanol) in Costa Rica and TCDC (Training Center for Development and Cooperation) in Tanzania specifically targeting the vocabulary and grammar needed by engineers working in hospitals. In addition to at least 20 hours of basic language training, volunteers receive about 20 hours of language training describing - in Spanish or Swahili - how to use and maintain medical equipment. All training occurs in the target region, either Central America or East Africa.

While no prior language training is required in the target language, participants do remarkably well, despite the relatively few hours of training they have received. The most likely explanation for their success is that very little language training is needed to train a nurse to use a piece of medical equipment, and much of the requisite vocabulary is similar to English.

The technical training is also specialized to our project and developed by EWH. Our training augments the already excellent theoretical training engineers receive with practical knowledge appropriate to the developing world. This training includes topics like testing medical equipment when specialized test equipment is not available and manufacturing alternative spare 
parts in resource poor environments. A unique and critical element in our volunteer engineers' training is the lessons on how to train medical staff and maintenance personnel across a cultural and linguistic barrier. Our engineers are taught the importance of training the hospital staff.

\section{The Second Four Weeks}

In the second four weeks of the summer program, the now trained engineers are sent in pairs to developing world hospitals in Tanzania and Central America. In most cases, they again stay with families. In other cases, they stay at the hospital in their staff housing. During their time at the hospital, the students accomplish multiple tasks. The most important two tasks are:

1) Repairing equipment that is broken

2) Training staff to use equipment that they already have

Historically, our students can put back into service $65 \%$ of the equipment they encounter. Twenty-eight percent of the equipment they work on has a broken power supply, including batteries, fuses and other related issues. Twenty-five percent of the equipment students touch during the summer is actually working, but the staff needs training in order to use the equipment.

In addition to these two tasks students also perform

1) Inventory - determining what the hospitals should request in donations

2) Preventative maintenance

3) Needs finding interviews

The last item on this list may need some explanation. While it is relatively easy to determine what the disease load of a particular hospital would be, in many cases, using American equipment to address those needs is inefficient, inappropriate or impossible. In order to understand why American equipment is not meeting their technology needs, students interview faculty and staff and try to determine what technology would help them. In some cases, the students fabricate a solution on the spot. In other cases, students return to the US to develop solutions or EWH posts the problems on the EWH website (www.ewh.org) for anyone to attempt to solve. Several universities across the US allow their students to solve posted problems for their senior design classes. EWH is also developing a new design competition that may address these problems as well.

\section{Lessons Learned}

\section{Hospital Selection}

When EWH first began the program, it was assumed that it would be difficult to find hospitals willing to accept engineers. We reasoned that they were students with limited experience and that they could become a burden on the hospitals.

This was not the case. In fact, the primary problem was careful selection of partner hospitals. 
EWH has now implemented an extensive selection process. Every hospital is subjected to a three-part review:

1) Telephone interviews with administrators

2) On-site visits

3) Analysis and selection

Lists of potential partners are generated from the ministry of health or by other partners in the selected country. At this stage, the country is evaluated for customs issues, level of corruption, safety, availability of embassies; US state department travel documents, concentration of hospitals, public transportation availability and safety, and the language and cultural compatibility with the program objectives.

Based on preliminary information obtained from the ministry of health (number of operating rooms, beds and technical staff), hospitals are selected for telephone interviews. From these interviews, EWH staff can confirm the hospitals interest in having engineers and their basic data (operating rooms, beds and staff). If there is technical staff, we can also determine their training level and interest. Approximately one recommended hospital in ten is selected for an on-site visit, or scouting trip.

During the on-site visit, the EWH staff interview the administration and staff of the hospital to make sure they understand and are interested in the EWH program. In addition, in depth surveys are conducted of:

1) available housing in the area

2) the safety and availability of public transportation

3) the availability of communication means, usually cell phone and/or internet

4) the type of equipment at the hospital and the amount of unused equipment

5) the work space for the students

6) the staff/supervisor that would be working with the student (number, training)

7) the proximity to an international airport

8) the proximity to potential destinations of interest for students

After returning to the US, all of the site visits are reviewed and hospitals are selected for the program by the director of the Duke-EWH Summer Institute and the EWH staff. This list of hospitals is then forwarded to the EWH board of directors for final approval.

Since implementing this multi-stage procedure, we have found that very few hospitals need to be dropped after a partnership is formed.

\section{Housing Selection}

Hospitals that are selected for the program are responsible for proposing a home stay or multiple home stays. Whether the hospital proposes one or more home stays for the participating engineers, Duke-EWH staff must determine if a home stay is acceptable to the program. The hospitals opinion is not sufficient. A Duke-EWH staff member must visit each home stay and 
return to visit that home stay every few years. A home stay should have running water, a phone (cell phone is acceptable) and electricity (full-time not required). The host parent (often the mother) should be friendly to strangers and able to communicate with those that have limited ability in the target language. The home should be clean and conveniently located. All home stays receive a negotiated amount of compensation, currently about $\$ 500$. In most cases, that amount is paid to the hospitals, who then pays the home stay.

\section{Assessment, Measurable Outcomes and Impact}

When we began the program, we assumed that he impact of our program would be self-evident. While we still believe that the impact is obvious, we have found it imperative to measure that impact in ways that can be communicated to donors, students and partners.

Duke-EWH tracks the following measurables for the summer institute.

1) Equipment repaired by students, and the type of repair action taken

2) Engineering hours spent training staff to use or maintain the equipment.

3) Spare parts selected and delivered to hospitals

4) Tool kits and reference material delivered with training

5) Hospitals visited for possible future support

6) Interviews on technology needs - summarized in a technology needs report.

An assessment is completed at the end of each summer. All of the measurables are reported at that time. Over multiple years, we also attempt to track the ability of the staff to maintain their own equipment. This is assessed using the inventory to understand the number of broken or unused pieces of medical equipment at the hospital.

By these measures, the Duke-EWH Summer Institute has been remarkably successful. The program has placed back into service over 1000 pieces of medical equipment worth more than $\$ 2,000,000$ over 5 years. Almost all of these repairs are contributions that the hospital could not make on its own. A total of 62 hospitals have been 60 hospitals have been visited by EWH staff, of which 23 are currently served by the Duke-EWH Summer Institute. In total, students in the program have gained over 30,000 hours of hands-on experience working with medical equipment in the clinical setting.

\section{A Learning Model for the Program}

Duke-EWH has always strived to improve each year. As the program grew, we found that this could not be accomplished without implementing a learning model for the program. For DukeEWH the learning model starts with basic data gathering. At the end of each summer, EWH staff and volunteers interview nearly every participant in an EWH program. Duke-EWH also interviews the home stays and hospitals. Every participant completes a report on the work they completed and the state of the hospital as they see it. Armed with this information, the learning model is completed every August when the EWH staff and president meet to review these 
outcomes and design changes (learn) that correct problems or improve the program. These recommended change lists create an archive of lessons learned.

\section{Student Selection}

For the summer of 2008, Duke-EWH received 97 applications for 50 spaces. The ratio of applications to spaces has been between 1.5 and 2.0 for many years. So, students must be selected for the program. During the first year of the program, EWH allowed students use almost any format for their application. However, the admissions committee, formed of four faculty from four different universities across the country found it too difficult to review the paperwork.

Starting in the second year, EWH standardized the application forms. Although many different formats have been tried over the years, the format that appears to lead to the most discriminating power includes the following elements: identifying information for the student, parents and school (requested for administrative purposes), information on their EWH affiliation and knowledge (used to help improve EWH), transcripts (used to identify any academic problems and verify that the required courses have been completed), a recommendation letter, an interview and six essays. The recommendation letter and interview are used as discriminating tools primarily when the other materials are insufficient to judge the candidate.

The basic information is used to eliminate students that have not adequate training, usually those below the level of sophomore engineers. However, applicants that have had a circuits course typically do better in the EWH program, often pushing the competition to exclude those below their junior year.

The essays have become the most powerful discriminatory tool, after the basic information and transcripts. Essays probe students' knowledge and exposure to clinical situations, language barriers, language training and experience, traveling alone, cultural diversity, and their reason for wanting to participate. In general, EWH has favored applicants that have sufficient language experience, travel experience alone and a desire to participate in the program that aligns with the mission of EWH.

Because of the large number of applicants, Duke-EWH staff now categorizes applicants into those that are clear candidates for the program, those are clearly not candidates for the program and those that are in-between. The admissions committee now only reviews those that are inbetween.

About $70 \%$ of applications for the Duke-EWH program come from candidates that already have their bachelor's degree, the majority of those participating immediately after graduation. Less than $10 \%$ of applicants are currently graduate students. On average about $50 \%$ of the participants are woman, far higher than national averages for comparable engineering programs.

\section{Other Lessons Learned}

Among the most critical lessons that we have learned for the program are: 
1. Relatively inexperienced engineers must work in pairs to be consistently effective. When we tried students alone, the cultural shock was excessive.

2. The entire summer program must be abroad. At first we did the training in the US and then had the students work overseas. While this allowed more flexible entry and was easier on the staff, the students' culture shock was so great that the first few days were wasted. Also, their language skills were relatively weak.

3. Students do better at integrating back into their home country if we provide them with an opportunity to share experiences with their peers. We now offer an end-of-trip conference for this purpose.

4. Most BME textbooks do not help in the developing world. Students do not have access to the specialized tools or spare parts. Now we use a textbook written by the students over the first three years of the program (Medical Instrumentation in the Developing World, available on Amazon.com). 